\title{
Influences of Using B20 Reformulated Type Fuel on a Heavy-Duty Diesel Engine Performances
}

\author{
Adnan Kadhim Rashid ${ }^{1}$, Bogdan Radu ${ }^{1, *}$, Alexandru Racovitza ${ }^{1}$, Radu Chiriac ${ }^{1,2}$ \\ ${ }^{1}$ UPB, Dept.of Thermo., Eng., Therm. and Ref. Mach., Spl. Independenței, nr 313, s.6,Romania \\ ${ }^{2}$ CMGPCE-EA7341, CNAM, Paris, France
}

\begin{abstract}
Starting from the need to replace up to $20 \%$ of the energetic fuel content as European Regulations have already stipulated for the years to come, B20 mixture fuel proves to receive an increasing recognition nowadays as an appropriate and alternative fuel for Diesel engines. Studies have provided that B20 increases engine efficiency under specific operating conditions together with a significant drop of the main emissions' levels. This paper is proposing a numerical analysis of the operating behavior of an IVECO Cursor 10 heavy-duty Diesel engine fueled with Diesel-Biodiesel B20 fuel, featuring the projections of the AMESIM simulation code.
\end{abstract}

Key words: Heavy-Duty Diesel Engine, Biodiesel-Diesel Fuel Mixture, High Efficiency, Emissions Decrease

\section{Introduction}

The benefits of using the biofuels of the fourth generation production by now in Diesel engines are obvious when comparing to the use of Diesel classic petroleum based fuel. Among the other promising fuels, Biodiesel has especially become an appropriate source to replace partially or even totally Diesel fuel. The advantages of Biodiesel compared to Diesel fuel are: a higher combustion efficiency, a higher autoignition capacity (a higher cetane number, within 42 and 67 units), a better biodegradability, together with lower carbon monoxide (CO) emissions [1,2,3]. The disadvantages of using Biodiesel are also to be mentioned, including slightly higher NOx emissions, cold start problems, lower heating value (LHV) and injection difficulties due to its higher viscosity.

Actually, Biodiesel is more expensive to be produced than Diesel fuel, animal and vegetable organic sources needing to be collected from more and more extended areas. Thus, current worldwide production of vegetable oil and animal fat is not enough to replace liquid fossil fuel. Therefore, of more increasing importance are the blends of other fuels prepared with Diesel fuel, like the bio-alcohols [4,5].

In its content Biodiesel has no aromatics, no sulfur, and provides about $10 \%$ to $11 \%$ weight oxygen. These characteristics lead to an important exhaust gas emission reduction in carbon monoxide, unburned Hydrocarbon (UHC) and particulate matter (PM). Regarding NOx emission, due to the more restricting standards, using Biodiesel with Diesel fuel and even with light fractions of gasoline, from multiple literature studies it might appears necessary to apply certain fueling methods combined with different several modes of air-fuel mixture 
formation and ignition, such as HCCI (Homogeneous Charge Compression Ignition), PCCI (Premixed Charge Compression Ignition), PPCI (Partially Premixed Compression Ignition) or RCCI (Reactive Controlled Compression Ignition) modes [6,7].

The critical problem of Biodiesel higher viscosity affects the characteristics of this fuel injection, because the higher the viscosity is, the poorest the fuel atomization becomes. High viscosity usually causes larger droplet sizes, lower vaporization rate, narrower injection spray angle, and longer in-cylinder penetration of the fuel spray. These aspects normally lead to overall poorer combustion, higher emissions, and increased oil dilution [8].

Combustion and emission characteristics of Diesel engine operated using Diesel fuel blended with Biodiesel were largely investigated. It has been proved that the higher the oil ratio in the blend is, the higher the break specific fuel consumption (BSFC) is and the lower the UHC and CO emissions are. The main exception for the emissions levels trend is the increase of the NOx emission, with no modifications brought to the engine and with no changing the air-fuel ratio. As it has been already mentioned, to improve fuel consumption and NOx emissions, there are some common techniques to be applied, such as modifying the fuel properties, by using metal based and oxygenated additives, antioxidants, using cold flow improving elements, or improving the exhaust gas treatment $[9,10]$.

Although Biodiesel is perfectly miscible in Diesel fuel at any ratios, the most common commercialized and tested blends between FAME (Fatty Acid Methyl Ester) and pure Diesel fuel are within the range B5-B30 (\%vol. Biodiesel-Diesel fuel), one of them being especially revealed as highly appropriate to be on large scale used, namely the B20 fueling mixture [11].

The main goal of this paper is to numerically analyze the engine system efficiency, performances and emissions, based on the use of a heavy-duty IVECO Cursor 10 Diesel type engine, when fueled with Diesel fuel and with Biodiesel-Diesel B20 fueling mixture.

\section{Differences between Diesel fuel and Biodiesel}

Biodiesel appeared as an alternative fuel to Diesel classic fuel, because its properties are comparable to those of the fossil fuel. Paper [1] extensively analyses the properties of both fuels, taking into account the fact that it has been developed a multitude of manufacturing sources for Biodiesel. Thus, it is constantly mentioned that viscosity, which the injection characteristics significantly depend on, has higher value for Biodiesel; Biodiesel has also a higher cetane number and a larger density comparing to Diesel fuel. Its pour point is high enough to generate difficulties when used at low temperatures cold starting. Biodiesel qualities as fuel are standardized in DIN EN 14214, its characteristics being expressed for the maximum and the minimum temperature scale values.

Cetane number values for different types of Biodiesel are varying in-between 37 and 62 units [12]. This fact could lead to an important variation of the autoignition delay when using Biodiesel as a single fuel. Same study [12] statues that Biodiesel low heating value almost constant of $37 \mathrm{MJ} / \mathrm{kg}$ for every tested type of.

The exposed elements show a close similarity between the physical properties of both analyzed fuel types (Biodiesel and Diesel fuel), making difficult to adopt a simulation model to highlight different occurring aspects during the in-cylinder combustion process, especially when using Diesel fuel - Biodiesel blends.

For a Diesel engine receiving liquid phase injected fuel, this one will penetrate the combustion chamber under a spray of droplets, which would vaporize, would mix with the air and than would burn. If using a mechanical injection type, describing the IVECO CURSOR 10 engine, Table 1, the viscosity of the fluid should generate a specific injection characteristic for each fuel. After the spray penetrates the combustion chamber volume, the vaporization rate of the fuel droplets becomes more important. Paper [8] describes an 
analysis of the vaporization duration of a droplet in case of a single fuel or a fuel mixture. The results reveal that the vaporization duration of a $100 \%$ Biodiesel droplet is within 7 to $20 \%$ greater than for a similar droplet of Diesel fuel and within 1.2 to $4 \%$ when speaking of a B20 (vol.20\% Biodiesel + vol.80\% Diesel fuel) fuel droplet, comparing to the same reference.

Table 1. Engine Cursor 10 -400 specifications [13]

\begin{tabular}{|c|c|}
\hline Maximum power [kW/hp] & $294 / 400$ \\
\hline Rated speed [rpm] & 2100 \\
\hline Number of cylinder & 6 \\
\hline Compression ratio & $16.5: 1$ \\
\hline Bore [mm] & 125 \\
\hline Stroke [mm] & 140 \\
\hline Cubic capacity [1] & 10.38 \\
\hline Fuel system & Direct injection mechanical \\
\hline Admission & turbocharged \\
\hline
\end{tabular}

In this context, in order to highlight the different combustion features separating pure Diesel fuel from a Biodiesel-Diesel fuel mixture it is necessary to adapt a computer model so that it could emphasize the injection modes, the vaporization and the unequal heating value of the fuel types.

\section{Characteristics of the fuel injection process}

The selected engine is an IVECO CURSOR 10-400 heavy-duty Diesel engine, with a maximal rating power of $294 \mathrm{~kW}$, corresponding to $2100 \mathrm{rpm}$. The engine uses a mechanical injection system, with a maximum injection pressure of $180 \mathrm{MPa}$. Therefore, the following model has been applied (see Fig. 1.).

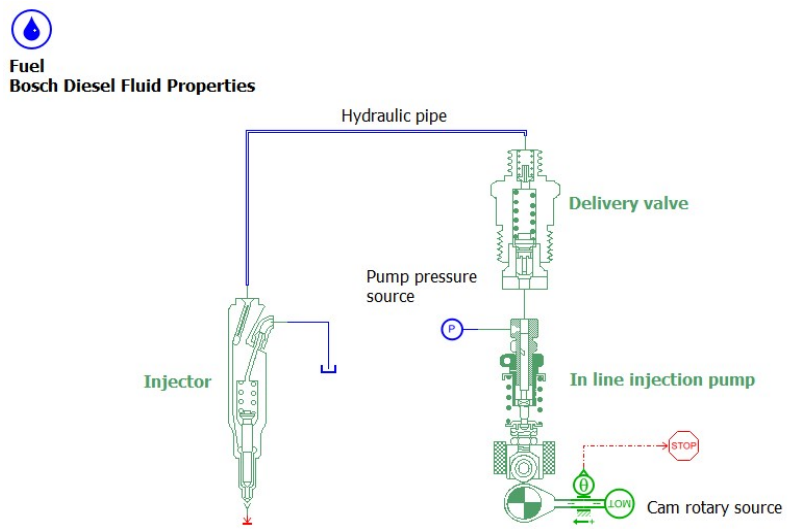

Fig. 1. Injection system model

The injection system consists in a pumping module containing the came acting on the tappet and consequently further on the piston of the pumping element (see Fig. 2). 


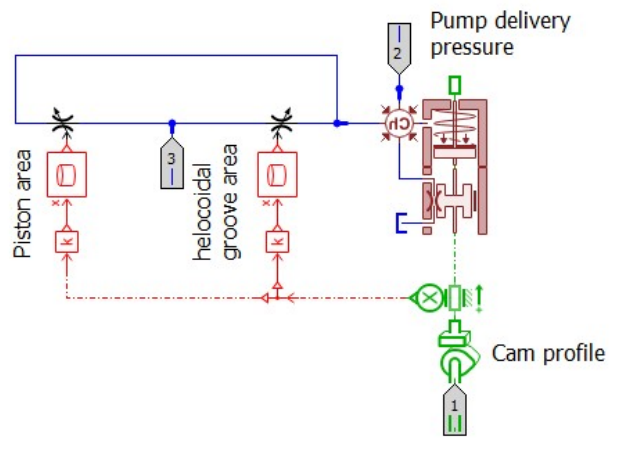

Fig. 2. Pumping element

The fuel flow is controlled by the piston compressing surface and by the section offered by the piston helical control edge. The engine has a pump-injector assembly and the highpressure pipe is very short. In case of using pure Diesel fuel, the injection pressure together with the needle lift are plotted in Fig. 3. The maximum of the injection pressure is 1800 bar.

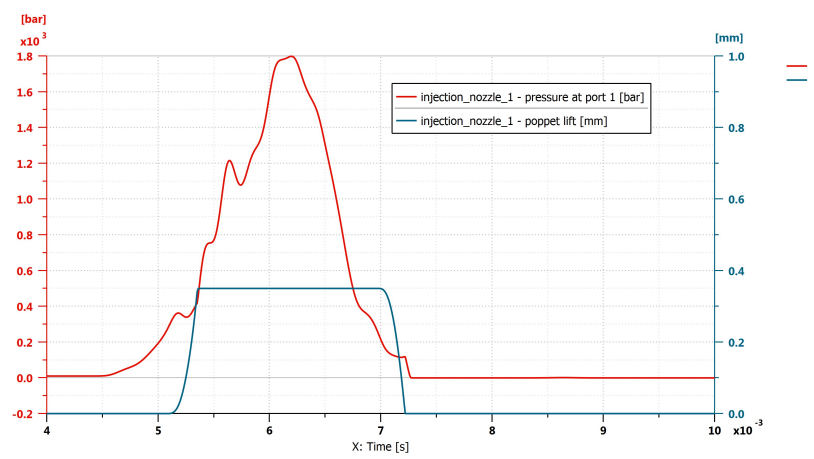

Fig. 3. Injection pressure and needle lift at Diesel

In case of using B20 fuel, the injection characteristic is highlighted in Fig. 4. The injection maximum pressure and the needle lift have both increased values than in the previous case.

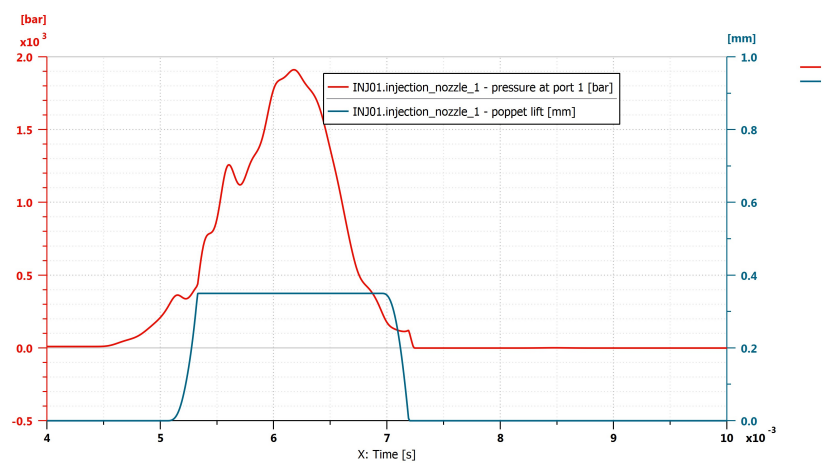

Fig. 4. Injection pressure and needle lift at B20

The system operating characteristics are comparatively presented in Fig.5. The maximum injection pressure is with 100 bar higher when using Biodiesel B20 fuel than in the classic situation for Diesel fuel due to its high viscosity. 


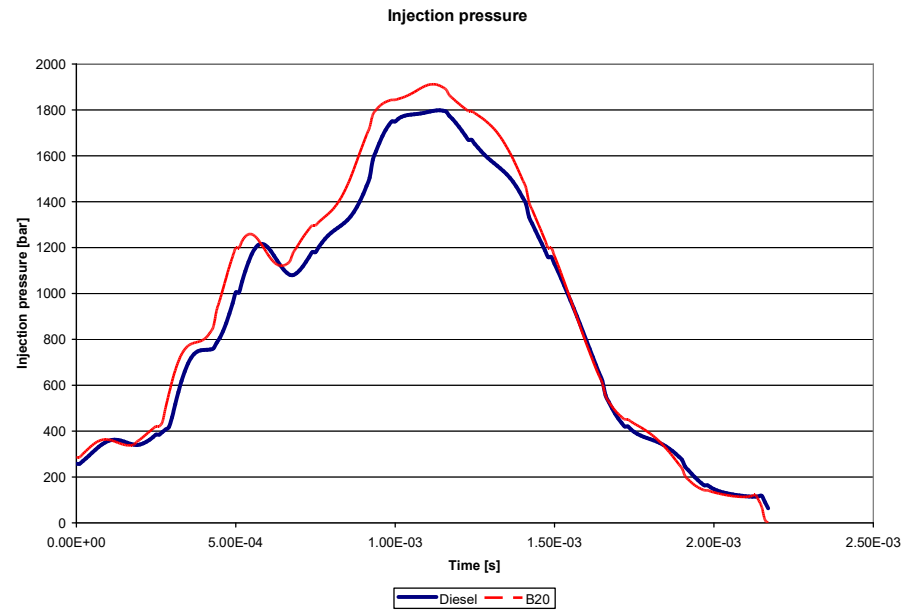

Fig. 5. Injection pressure variation vs. time

Referring to the injection fuel flows, small differences occur between the two operating situations (see Fig. 6). The image contains also the polynomial interpolation functions, necessary to generate a function for the injector model in engine model.

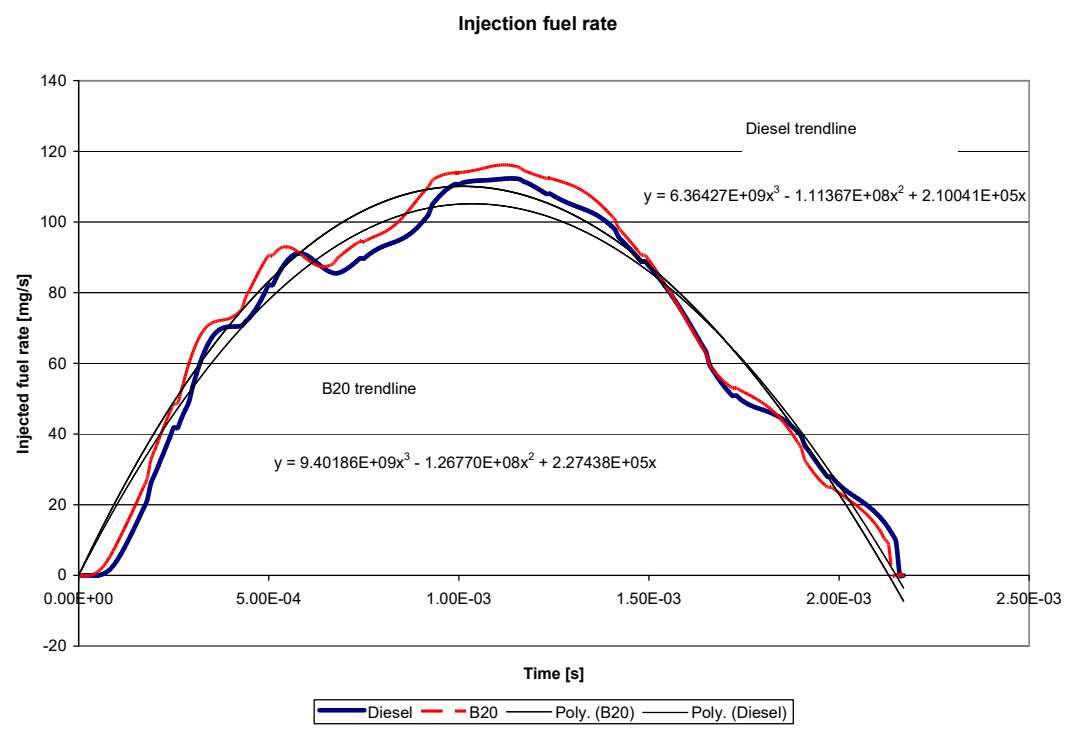

Fig. 6. Injection fuel rate and trendline

From the total injected mass point of view, the differences are rather small, from $146 \mathrm{mg}$ Diesel injected fuel to about $152 \mathrm{mg}$ of B20 injected fuel. Following the simulations, one common scenario has been used, the one in which both fuel types on-cycle injected quantities are equally to $146 \mathrm{mg}$.

\section{Modelling in-cylinder processes}

The fuel is injected inside the cylinder through the pumping element, which applies as a main parameter an interpolation function of the injected fuel flow. This one is taken from the injection system model for each fuel apart. In order to describe the development of the 
in-cylinder processes, the AMESIM numerical code uses Chmela [14] proposed model, related to the vaporization and the mixing rates of the fuel droplets sprayed into the cylinder. The heat release rate for the applied model is based on the dependence on four parameters: the vaporization specific time, the mixing duration, the constant of the injection turbulence dissipation and one constant depending on the effect of the residual burned gas on the combustion process. In the analysis of the air-fuel mixture formation it is assumed that the only difference between the two cases (Diesel fuel and Biodiesel B20 mixture) represents the vaporization duration of the droplets, for the use of Biodiesel this duration is reduced as it is reported by reference [8]. The other values depending on the autoignition process have been kept constant when comparatively analyzing the two fuels.

\subsection{Reference results obtained for Diesel fuel}

When fuelling with Diesel fuel the obtained rated power was $294 \mathrm{~kW}$ at $2100 \mathrm{rpm}$, corresponding to fuel dose amount of $148 \mathrm{mg}$ per cycle and cylinder, meaning a BSFC value of $190 \mathrm{~g} / \mathrm{kWh}$. The cylinder peak fire pressure was $23 \mathrm{MPa}$, the relative air-fuel ratio was 1.5 and the supercharging pressure was 2.4 bar.

\subsection{Results obtained for B20}

The different properties of B20 compared to Diesel fuel were: a lower heat value of $41.4 \mathrm{MJ} / \mathrm{kg}$ for Biodiesel vs. $44 \mathrm{MJ} / \mathrm{kg}$ for Diesel fuel, the vaporization duration for Biodiesel decreased by 3\% [8] comparing to Diesel fuel and the injection characteristic for B20 shaped as in Fig. 6. When using B20 fuel, a maximum rating power is $270 \mathrm{~kW}$. The supercharging pressure was 2.31 bar, the peak fire pressure was $21 \mathrm{MPa}$ and the relative air-fuel ratio was 1.46 .

\subsection{Comparison between Diesel fuel and B20 fuel}

The heat release characteristic (see Fig. 7) has the same shape for both types of the used fuels, only the released energy being different due to the higher heating value of Diesel fuel.

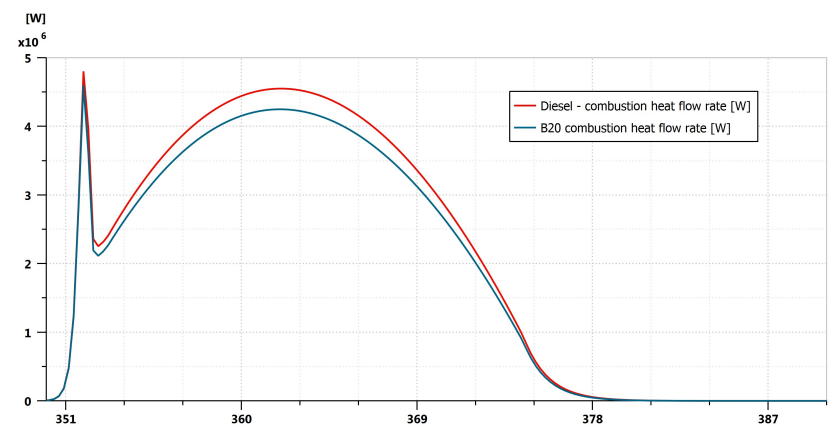

Fig. 7. Comparison of the heat release rates for Diesel fuel and B20

Corresponding to the first premixed air-fuel mixtures combustion stage, the variation of the released energy is practically the same in both cases (see Fig. 8). The unit used for this graph are watts and, in correlation with lower heat value for B20, indicates the influence of the faster B20 vaporization rate versus Diesel fuel because a larger amount of fuel is vaporised in this period of time. 


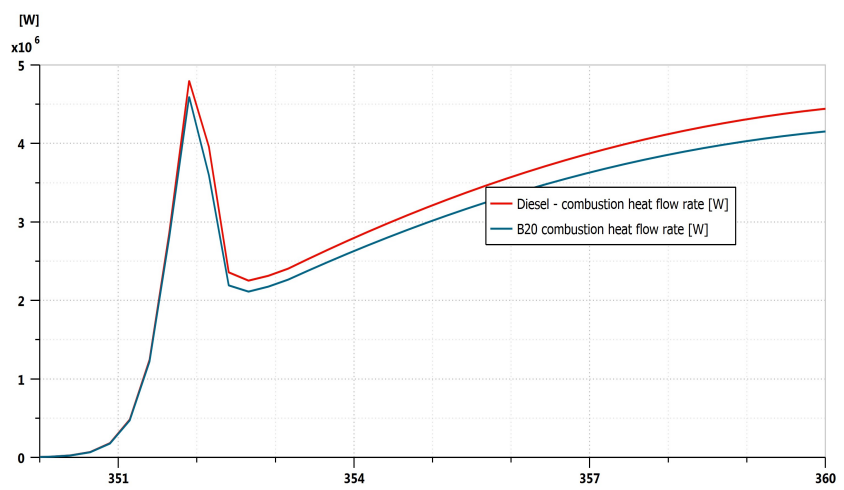

Fig. 8. Combustion heat release rate for Diesel fuel and B20 (detail)

The in-cylinder processes are affected by the injection characteristic, by the vaporization rate and by the lower heating value of each fuels. Thus, the peak fire pressure (showed in Fig.9) is $22 \mathrm{MPa}$ in case of Diesel fuel vs. $21 \mathrm{MPa}$ in case of B20 fuel.

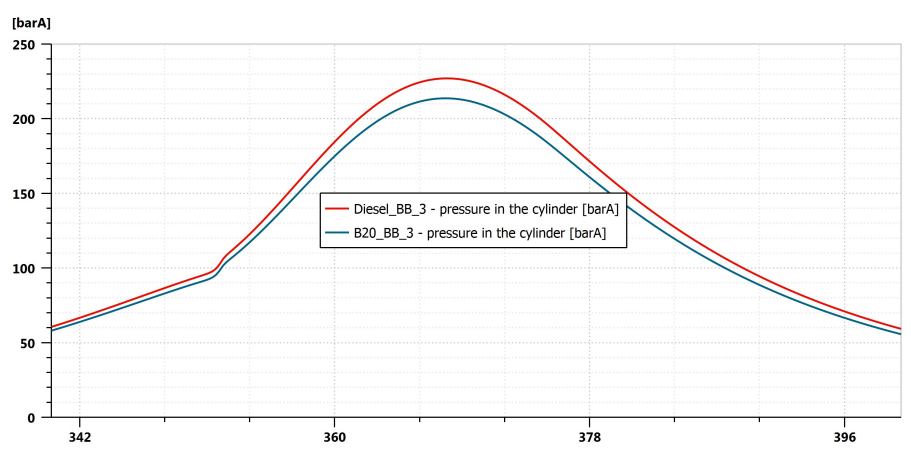

Fig. 9. The indicated pressure vs. crankshaft position

The in-cylinder temperatures have similar variation as the pressure traces following in Fig. 10. This is explainable by the way in which the turbocharging system responses when replacing the original Diesel fuel, respectfully to the fact that the turbocharging group speed decreases from $83800 \mathrm{rpm}$, when using Diesel fuel to $81700 \mathrm{rpm}$, correspondingly when using B20. In these conditions the relative air-fuel ratio drops from 1.5 to 1.46 and the temperature variation during the combustion process is very similar between the two fuels.

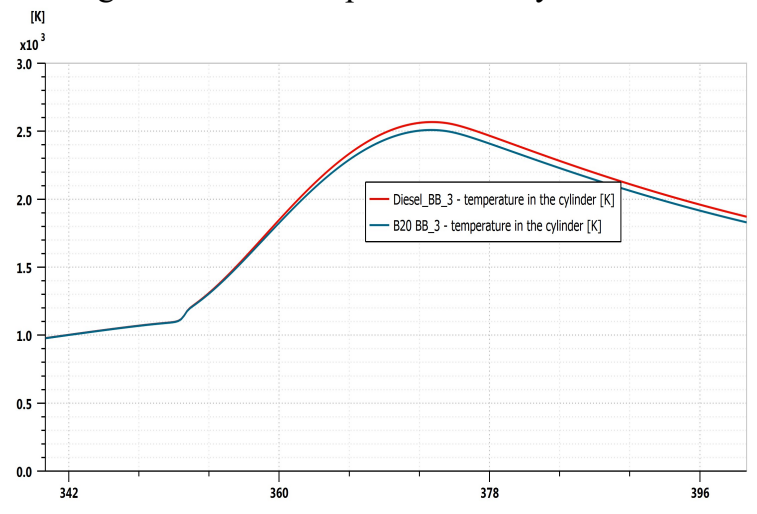

Fig. 10. In-cylinder temperature variation 
The obtained results concerning the in-cylinder processes allow a further evaluation of the way in which the pollutant emissions are generated.

\section{Conclusions}

The next conclusions can be summarized as follow:

1. Despite the different of some physical properties, existing between the two fuels considered, no major changes have been identified by simulation on the injection characteristics; an increase of $5.5 \%$ in maximum injection pressure form 1800 bar for Diesel fuel to 1900 bar for Biodiesel B20 which does not change by more than $4 \%$ the fuel amount per cycle and cylinder;

2. This slight alteration of the fuel amount when using B20 alters the relative airfuel ratio which in turns associated with the reduction of the lower heating value modifies the heat release characteristics and the in-cylinder pressure and temperature; the corresponding peak fire pressure and the peak fire temperature are reduced by $4.5 \%$ and respectively by $4 \%$.

3. As a general conclusion, taking into account these model results and the experimental knowledge of the authors, the use of a fuel that includes $20 \%$ biodiesel in a conventional engine without constructive adaptations, will not generate essential differences in the engine running.

\section{References}

1. P. Saxenaa, S. Jawaleb, M. Joshipurac ELSEVIER Proc. Eng. 51 (2013)

2. K. A. Sorate, P. Bhale ELSEVIER Ren. and Sust. Energy Reviews 41 (2015)

3. P. Tamilselvana, N. Nallusamyb, S. Rajkumarb ELSEVIER Ren. and Sust. Energy Reviews 79 (2017)

4. I. Yahuza, H.Dandakonta, M.E.Ibrahim J. of Bio-process. \& Biotech., vol.6/2016

5. Ramona Stefanescu Mihaila ELSEVIER Ethanol Sc. and Eng., 2019, pp.523-535

6. A. Racovitza, B. Radu, M. Aldhaidhawi, R. Chiriac EAEC-ESFA, Springerlinks 2016

7. M. Gharbanpour, R. Rasekhi ELSEVIER Fuel 106 (2013)

8. Qubeissi, M. ELSEVIER Applied Thermal Engineering (2018)

9. Li Han, Y. Wenming, Z. Dezhi, Yu Wenbin ELSEVIER, App. Therm Eng. 137 (2018)

10. P.S. Varun, K.T. Samaresh, S. Rituparn, K.Naresh ELSEVIER, Renewable and Sustainable Energy Reviews 79 (2017)

11. M. Aldhaidhawi Study on Performance, Emissions and Combustion Charac. of a Diesel Engine Fueled with Biodiesel B20, PhD Thesis, Politehnica Univ. Buc., (2017)

12. I.Barabás and I.A. Todoruţ Biodiesel http://cdn.intechweb.org/pdfs/23666.pdf

13. http://www.powertechengines.com/IvecoData/CURSOR-10.pdf

14. F. Chmela, C. Orthaber, SAE paper 1999-01-0186, (1999) 